\title{
Hot Deformation Behavior and Processing Maps of Ti-6554 Alloy for Aviation Key Structural Parts
}

\author{
Qi Liu®, Zhaotian Wang, Hao Yang and Yongquan Ning *® \\ School of Materials Science and Engineering, Northwestern Polytechnical University, Xi'an 710072, China; \\ liuqi2018@mail.nwpu.edu.cn (Q.L.); wzt199604043138@163.com (Z.W.); yryanghao@126.com (H.Y.) \\ * Correspondence: luckyning@nwpu.edu.cn; Tel.: +86-29-8849-2642
}

Received: 2 June 2020; Accepted: 17 June 2020; Published: 21 June 2020

\begin{abstract}
With the development of the aviation industry, the performance requirements of materials for aviation large-scale structural parts are getting higher and higher. Ti-6554 alloy is the material of choice for aviation large-scale structural parts, but its forming process window is narrow and its microstructure is sensitive to process parameters, which affects the performance of the alloy. By adjusting the existing hot deformation process, it is of great significance to improve the properties of the alloy. Hot compression tests of Ti-6554 alloy were carried out at temperatures of $715-840{ }^{\circ} \mathrm{C}$ and strain rates of $0.001-1 \mathrm{~s}^{-1}$. The results show that the flow stress and peak stress increased significantly with the increase of strain rate. At the same strain rate, the strain required for the stress to reach the peak point is smaller with the temperature increases. When the deformation temperature is below the phase transition point, the volume fraction and size of primary $\alpha$ phase gradually decrease with the increase of deformation temperature, while when the temperature is above the phase transition point, with the increase of deformation temperature, $\beta$ grains grow up gradually, and the grain boundary bending effect is more obvious. The hyperbolic-sine Arrhenius constitutive equation was established. The correlation coefficient between experimental data and model calculated data reached 0.994. It indicates that the stress constitutive model proposed in this study can accurately reflect the stress characteristics of Ti-6554 alloy. Based on the dynamic material model, the processing maps of the alloy were established. The optimum hot deformation parameters range of the alloy was determined by analyzing the processing maps: the deformation temperature range of $800-830^{\circ} \mathrm{C}$, the strain rate range of $0.001-0.01 \mathrm{~s}^{-1}$. Through the analysis of the processing maps, the instability regions in the process of cross-phase forging can be effectively avoided, and the performance of the forging can be effectively improved.
\end{abstract}

Keywords: Ti-6554 alloy; hot deformation; microstructure evolution; constitutive model; processing map

\section{Introduction}

Metastable $\beta$ titanium alloy has high specific strength, deep hardenability, good corrosion resistance, and excellent processing performance, it is the material of choice for manufacturing large structural parts of aircraft [1-4]. Ti-6554 (Ti-6Cr-5Mo-5V-4Al) alloy is a new type of metastable beta high strength and high toughness titanium alloy, which is mainly used for manufacturing large-scale aviation structural parts, such as aircraft frames and landing gear. Its [Mo $]_{\mathrm{eq}}$ is 13.3 and $[\mathrm{Al}]_{\mathrm{eq}}$ is $4[5,6]$. This alloy is a titanium alloy with high structural efficiency and excellent comprehensive performance. When the tensile strength of Ti-6554 alloy reaches $1270 \mathrm{MPa}$, its fracture toughness can reach more than $80 \mathrm{MPa} \cdot \mathrm{m}^{1 / 2}$. Its strength and toughness are better than BT-22 and Ti-1023 [7-9]. However, the alloy has large deformation resistance and poor thermal conductivity during thermal deformation. The flow stress and the microstructure are sensitive to the thermal deformation parameters $[10,11]$. In the actual 
production, various macroscopic and microscopic defects are easily generated, and the mechanical properties of the forgings are reduced. At present, there are few studies on the flow behavior and microstructure evolution of this alloy during thermal deformation. Hence, in order to obtain good performance of the alloy, it is necessary to study the flow behavior of the alloy.

During the thermal deformation of materials, the constitutive model can be used to describe the effects of deformation temperature, strain rate, and strain on the flow behavior, which is helpful to reduce the unnecessary forming defects and costs. In recent years, a large number of constitutive equations have been proposed or improved, which can be divided into three categories [12-14]: phenomenological, physically-based and artificial neural network (ANN). The phenomenological constitutive model is a model developed in the past to simulate the forming process of metals, alloys or composites at high temperature and high strain rate, Arrhenius constitutive relation is a typical representative of this constitutive model [15-17]. The model is widely used to describe the flow behavior of alloy materials such as titanium alloy [18,19], magnesium alloy [20], aluminum alloy [21], and nickel-base superalloy [22]. The physically-based constitutive model is based on the microscopic mechanism within the material to establish a model related to the deformation mechanism [23]. Due to the fact that the actual forming often involves multiple deformation mechanisms at the same time, the solution of the model parameters is relatively complicated, and the theory may deviate greatly from the reality, which leads to the difficulty in the test and application of the model. ANN model is composed of many simple and widely connected units. These units are arranged in layers, which can dynamically respond to input information and process information, and can describe complex nonlinear relationships [24]. However, ANN model has poor generality and requires long learning time. Therefore, for finite element simulation of engineering applications and macroscopic deformation, the phenomenological constitutive model is more practical.

The processing maps can be used as the basis to evaluate the machining performance of materials, and it is a powerful auxiliary tool for the process design of metal materials. At present, there are about two types of processing maps that are highly recognized. One is the Raj [25] processing maps based on the atomic model, and the other is the processing maps based on the dynamic material model (DMM). The Raj processing maps is only effective under steady-state conditions, and general complex alloys cannot be used directly, so it has great limitations in practical applications. The processing maps developed on the basis of DMM not only reflects the region where the specific deformation mechanism of specific microstructure is located, but also describes the unstable state that should be avoided during the hot processing [26]. Therefore, this paper chooses the processing maps based on DMM. The plastic deformation mechanism under different deformation conditions can be predicted by using the processing maps, and the unstable deformation parameters during the hot deformation process can be avoided. The cross-phase forging process can be guided by the processing maps.

In this study, the thermal deformation behavior of Ti-6554 alloy was studied by hot simulation compression test within the deformation temperatures of $715 \sim 840{ }^{\circ} \mathrm{C}$ and strain rates of $0.001 \mathrm{~s}^{-1} \sim 1 \mathrm{~s}^{-1}$. Through the analysis of the test results, the effects of deformation temperature and strain rates on the flow stress and microstructure evolution of the alloy were studied. The hyperbolic sinusoidal Arrhenius constitutive equation was established and the accuracy of the model was tested, which provides reference for the numerical simulation of the forming process of Ti-6554 alloy. Finally, the processing maps of the alloy was established, and the optimum range of hot processing parameters were determined. Through the analysis of the processing maps, the better forging process parameters of the cross-phase region were determined, which provides a reference for improving the service performance of forgings.

\section{Materials and Methods}

The test material was Ti-6554 alloy hot forging bar. It was prepared by three times of vacuum arc remelting, and the chemical composition is shown in Table 1. The phase transition point was $790( \pm 5)^{\circ} \mathrm{C}$ as measured by metallographic method. A sample having a diameter of $8 \mathrm{~mm}$ and a 
height of $12 \mathrm{~mm}$ was taken out from the original bar blank. Figure 1 shows the original microstructure of Ti-6554 alloy bar. From Figure 1, we can see that the microstructure of the sample is equiaxed $\alpha$ phase and $\beta$ matrix, and its specific morphology is: along the grain boundary, there are slightly larger equiaxed $\alpha$ phase, while in the $\beta$ matrix within the crystal, there are even smaller equiaxed $\alpha$ phases, and the number of equiaxed $\alpha$ phases in the crystal is obviously more. The volume fraction of the equiaxed $\alpha$ phase is about $13 \%$, and the average diameter is about $5 \mu \mathrm{m}$.

The compression test was carried on a Gleebe-1500D thermal simulation tester (DSI, America) with six sets of deformation temperatures $\left(715,735,755,775,810,840{ }^{\circ} \mathrm{C}\right)$ and four sets of strain rates $\left(0.001,0.01,0.1,1 \mathrm{~s}^{-1}\right)$, the height was reduced by $60 \%$ to $4 \mathrm{~mm}$. Before the experiment, tantalum pieces coated with glass lubricant were placed on both ends of the sample to reduce the friction between the table and the sample. During the experiment, the heating rate of the sample was set to $10^{\circ} \mathrm{C} / \mathrm{s}$. When the temperature reached the set value, the sample was kept warm for 5 min in order to make the temperature of the center of the sample consistent with that of the surface. After the experiment, the samples were quenched immediately to retain the high temperature microstructure of the deformed samples. The system can automatically collect the relevant data in the process of compression. The sample was mechanically polished and then etched with a solution of $2 \mathrm{~mL} \mathrm{HF:10}$ $\mathrm{mL} \mathrm{HNO}_{3}: 88 \mathrm{~mL} \mathrm{H}_{2} \mathrm{O}$. Observe and take metallographic photographs under the OLYMPUS GX-71 optical microscope (Olympus, Tokyo, Japan).

Table 1. Chemical composition of Ti-6554 alloy (mass fraction, \%).

\begin{tabular}{cccccccc}
\hline Cr & Mo & V & Al & Fe & Si & C & Ti \\
\hline 5.7 & 4.7 & 4.81 & 3.93 & 0.080 & 0.028 & 0.025 & Bal. \\
\hline
\end{tabular}



(a)

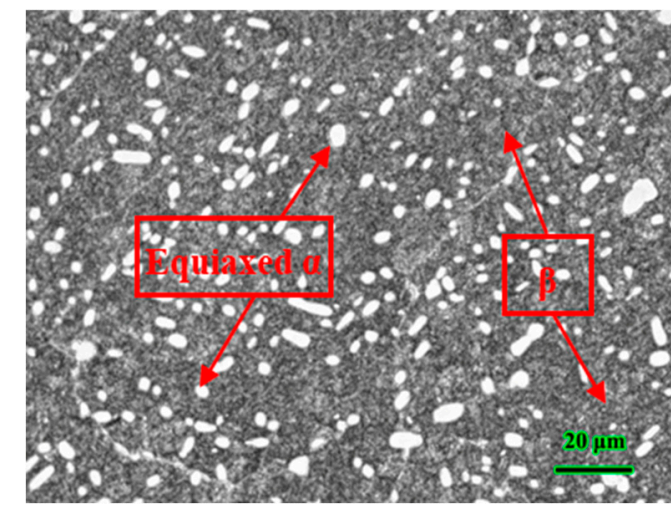

(b)

Figure 1. The initial microstructure of Ti-6554 alloy bar. (a) Microstructure at 50× magnification; (b) Microstructure at 500× magnification.

\section{Results and Discussion}

\subsection{Flow Stress Characteristics}

The true stress-strain curves of Ti-6554 titanium alloy obtained through the thermal compression test are depicted in Figure 2. It can be seen from the figure that Ti-6554 titanium alloy has similar true stress-strain curve variation rule under different strain rates. In the early deformation stage, the flow stress rises rapidly with increasing strain. The reason is that at the early stage of deformation, dislocations proliferate and accumulate at the grain boundary through slip. The increase of dislocation density makes the critical shear stress of slip increase rapidly [27]. Therefore, in the early deformation stage, the overall work hardening rate of the deformed alloy is relatively high. When the strain reaches the critical strain of dynamic recrystallization (generally less than 0.1 [28]). With the beginning of dynamic recrystallization (DRX), the dynamic softening effect gradually increases, and the work 
hardening rate of the alloy decreases. The dynamic softening and work hardening reached the first dynamic equilibrium at the peak strain [29]. After that, it enters the dynamic softening stage, and the dislocation network generated in the previous stage evolves to form a large number of new crystal nuclei, which absorb the surrounding dislocation and gradually grow into dynamic recrystallized grains, reducing the dislocation density in the alloy and weakening the work hardening effect. At last, it entered the steady state flow stage. The dislocation growth rate in the alloy was basically equal to the consumption rate of the growth of new grain nucleation with the further increase of strain, and the work hardening and dynamic softening reached the second dynamic equilibrium.

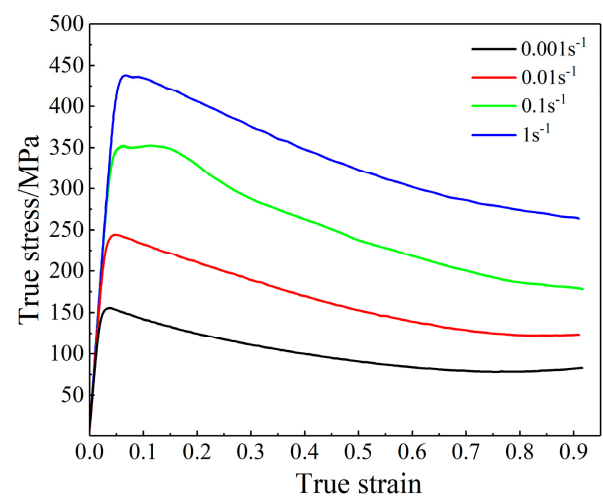

(a)

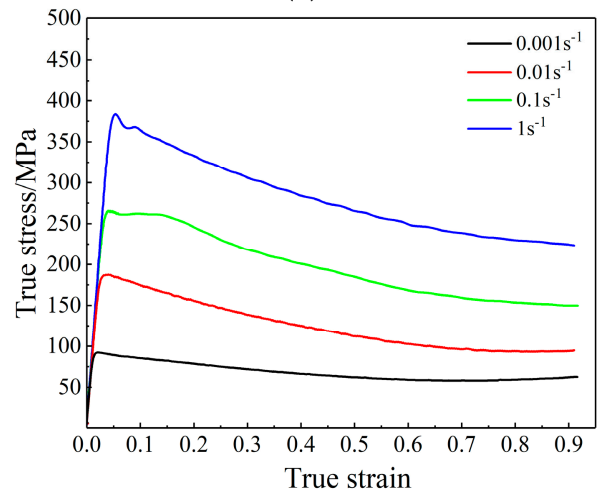

(c)

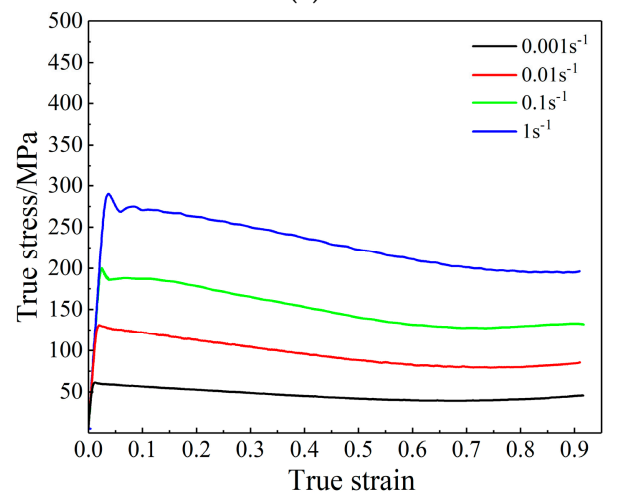

(e)

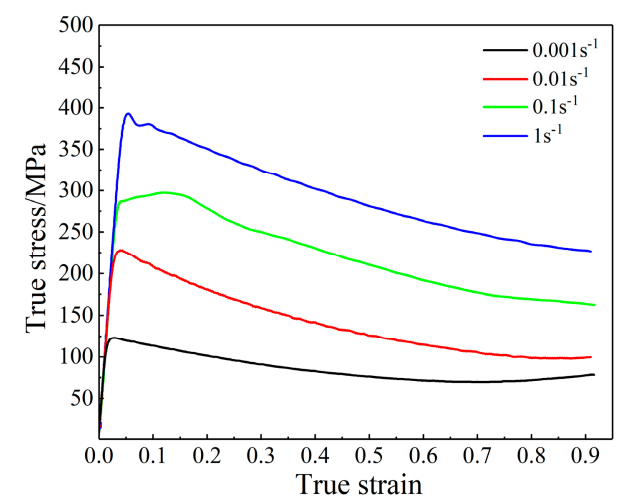

(b)

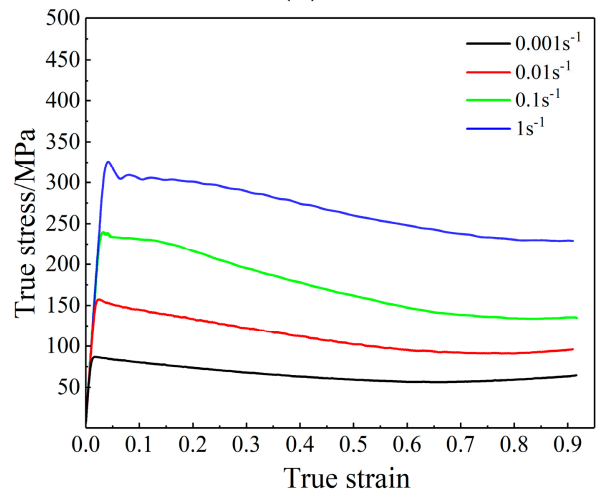

(d)

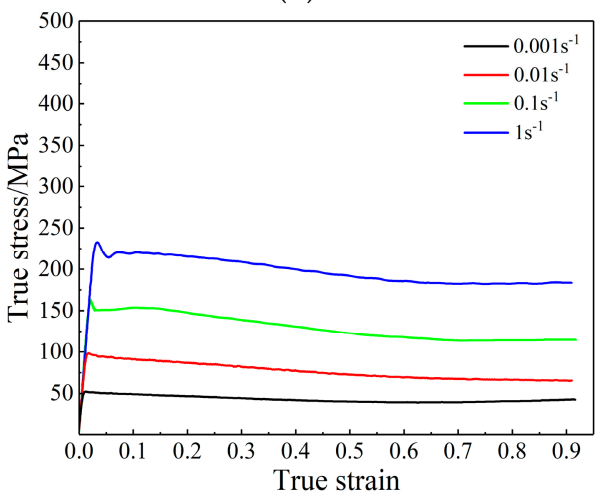

(f)

Figure 2. The true stress-strain curves of Ti-6554 alloy under deformation temperatures of (a) $715^{\circ} \mathrm{C}$; (b) $735{ }^{\circ} \mathrm{C}$; (c) $755^{\circ} \mathrm{C}$; (d) $775{ }^{\circ} \mathrm{C}$; (e) $810{ }^{\circ} \mathrm{C}$; (f) $840{ }^{\circ} \mathrm{C}$.

Thermal deformation process parameters have an important effect on the microstructure and properties of the material after hot forming. It can be seen from Figure 2 that the flow stress of Ti6554 alloy has high strain rate sensitivity, and its main characteristics are as follows: 
(1) Under the same temperature conditions, the greater the strain rate, the greater the stress corresponding to the same strain. This is because when the strain rate is large, the time of unit strain is short, a large number of dislocations move simultaneously in a short time, which will increase the distortion degree of Ti-6554 titanium alloy, leading to the increase of critical shear strain force, the decrease of grain boundary slip momentum, and leading to the increase of work-hardening rate.

(2) Under the condition of high strain rate, the stress-strain curves have a sharp initial stress peak, discontinuous yield occurs, and then continues to soften. This is mainly because: in the elastic deformation stage, the dislocation density in Ti-6554 alloy is low, but when the plastic deformation occurs, the dislocations starts to move and multiply, when the dislocation movement to the grain boundary will be blocked and produce plug accumulation, so that the stress increases rapidly. As the dislocation accumulates until the critical value is exceeded, dynamic recovery (DRV) will occur in the $\beta$ phase, and the dislocation of the plugging product will move through climbing, cross slip, and other means, and a large number of dissimilar dislocations will annihilate each other, so that the dislocation density in the grain will decrease, which shows that the stress will drop significantly in a short time.

(3) At the same strain rate, the strain required for the stress to reach the peak point is smaller with the temperature increases. This is mainly because: when the alloy is deformed at a higher temperature, a small amount of recrystallization occurs under a smaller strain, which causes the alloy to enter the softening stage in advance and presents the characteristics of an earlier peak point in the curve.

\subsection{Establishment of Constitutive Model}

Arrhenius equation is widely used to describe the relationship between material flow stress and deformation parameters [30]. Its specific equation is:

$$
\dot{\varepsilon}=\operatorname{AF}(\sigma) \exp \left(-\frac{\mathrm{Q}}{\mathrm{RT}}\right)
$$

$\mathrm{F}(\sigma)$ is the stress function, which has the following three forms under different stress states:

$$
\mathrm{F}(\sigma)= \begin{cases}\sigma^{\mathrm{n}^{\prime}} & \alpha \sigma<0.8 \\ \exp (\beta \sigma) & \alpha \sigma>1.2 \\ {[\sinh (\alpha \sigma)]^{\mathrm{n}}} & \text { for all } \sigma\end{cases}
$$

where $\dot{\varepsilon}$ is deformation strain rate $\left(\mathrm{s}^{-1}\right)$, T is deformation temperature $(\mathrm{K}), \sigma$ is the flow stress (MPa), $R$ is gas constant $\left(8.31 \mathrm{~J} \cdot \mathrm{mol}^{-1} \cdot \mathrm{K}^{-1}\right), \mathrm{Q}$ is activation energy $\left(\mathrm{KJ} \cdot \mathrm{mol}^{-1}\right), \alpha=\beta / \mathrm{n}^{\prime}, \mathrm{A}, \beta, \mathrm{n}$, and $\mathrm{n}^{\prime}$ are material constants. The power exponent-type is usually the preferred method for describing creep, but it cannot be used when the stress is large. Under the conditions of relatively low temperature or high strain rate, the exponential type is applicable. The hyperbolic-sine type can be applied to various temperatures and strain rates [31]. Therefore, the hyperbolic sine is more general expression. In order to obtain the above material constants, substitute Equation (2) into Equation (1), and then take natural logarithm for both sides at the same time to get the following formula:

$$
\begin{gathered}
\ln \dot{\varepsilon}=\mathrm{n}^{\prime} \ln \sigma+\left(\ln \mathrm{A}_{1}-\frac{\mathrm{Q}}{\mathrm{RT}}\right) \\
\ln \dot{\varepsilon}=\beta \sigma+\left(\ln \mathrm{A}_{2}-\frac{\mathrm{Q}}{\mathrm{RT}}\right) \\
\ln \dot{\varepsilon}=\operatorname{nln}[\sinh (\alpha \sigma)]+\left(\ln \mathrm{A}-\frac{\mathrm{Q}}{\mathrm{RT}}\right)
\end{gathered}
$$

In addition, the thermal deformation condition can be expressed by the Zener-Hollomon [32] parameter as follows:

$$
\mathrm{Z}=\dot{\varepsilon} \exp \left(\frac{\mathrm{Q}}{\mathrm{RT}}\right)=\mathrm{AF}(\sigma)=\mathrm{A}[\sinh (\alpha \sigma)]^{\mathrm{n}}
$$


Through the transformation of Equation (6), the expression of stress can be obtained:

$$
\sigma=\frac{1}{\alpha} \ln \left\{\left(\frac{\mathrm{Z}}{\mathrm{A}}\right)^{\frac{1}{\mathrm{n}}}+\left[\left(\frac{\mathrm{Z}}{\mathrm{A}}\right)^{\frac{2}{\mathrm{n}}}+1\right]^{\frac{1}{2}}\right\}
$$

The results of thermal simulation compression test show that the stress value of Ti-6554 alloy varies greatly under different thermal deformation parameters. However, according to Figure 2, most of the stress values tend to be stable or only change in a small range as the strain increases when the true strain reaches 0.6 . It can be considered that the Ti-6554 alloy has entered the steady state flow stage. Therefore, stress $\sigma_{0.6}$ is selected to establish the constitutive equation of Ti-6554 alloy. Since the large difference between the deformation microstructure of the titanium alloy in different phase region, in order to further understand its phase region characteristics, the constitutive equations of the $\alpha+\beta$ phase region and the $\beta$ region are solved separately.

According to Equations (3) and (4), the constants $n^{\prime}=\partial \ln \dot{\varepsilon} / \partial \ln \sigma$ and $\beta=\partial \ln \dot{\varepsilon} / \partial \sigma$ are the coefficients of $\ln \sigma-\ln \dot{\varepsilon}$ and $\sigma-\ln \dot{\varepsilon}$ at a certain strain, respectively. When the true strain is 0.6 , the relationship diagrams of $\ln \sigma-\ln \dot{\varepsilon}$ and $\sigma-\ln \dot{\varepsilon}$ at different temperatures are drawn respectively, as depicted in Figure 3. The least square method is used to fit the data points linearly, and the values of $\mathrm{n}^{\prime}$ and $\beta$ in different phase regions can be obtained, the specific values are shown in Table 2. Hence, we can derive the value of $\alpha$ in different phase regions according to formula $\alpha=\beta / n^{\prime}$, and the specific $\alpha$ value is shown in Table 2 .

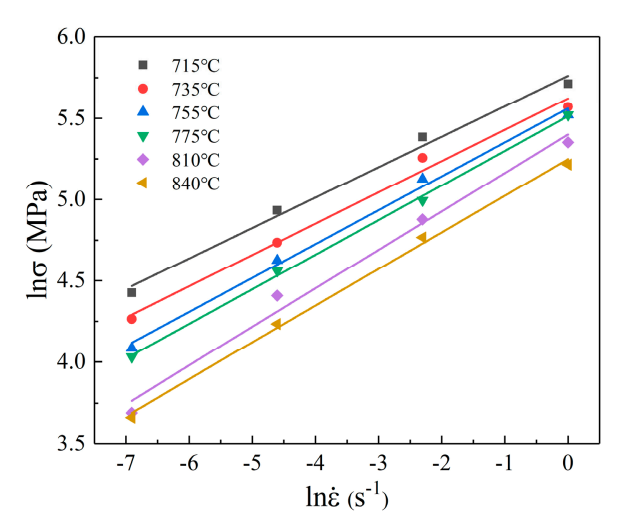

(a)

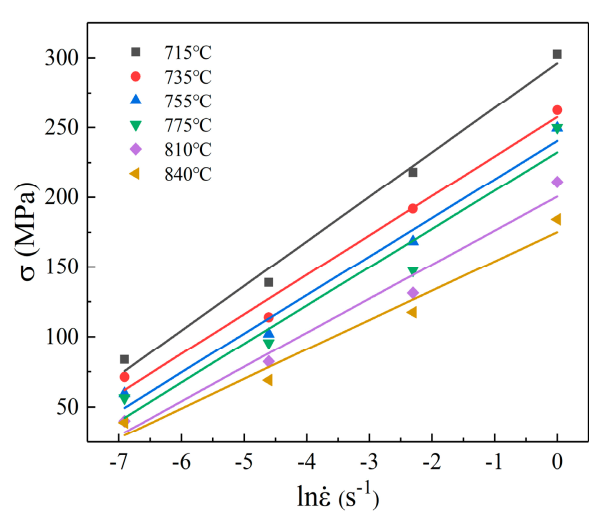

(b)

Figure 3. The relationships of (a) $\ln \sigma$ and $\ln \dot{\varepsilon} ;(\mathbf{b}) \sigma$ and $\ln \dot{\varepsilon}$.

Table 2. Constitutive model parameters for Ti-6554 alloy.

\begin{tabular}{ccc}
\hline \multirow{2}{*}{ Model Parameters } & \multicolumn{2}{c}{ Parameters Values } \\
\cline { 2 - 3 } & $\mathbf{A}+\boldsymbol{\beta}$ Phase & $\boldsymbol{\beta}$ Phase \\
\hline $\mathrm{n}^{\prime}$ & 5.003402 & 4.331211 \\
$\beta$ & 0.034779 & 0.04428 \\
$\alpha$ & 0.006951 & 0.010223 \\
$\mathrm{n}$ & 3.706985 & 3.197382 \\
$\mathrm{Q}$ & 244.8959 & 183.815 \\
$\ln \mathrm{A}$ & 24.82687 & 16.08101 \\
\hline
\end{tabular}

Find the partial differential of Equation (5) about $\ln [\sinh (\alpha \sigma)]$, and sort it out as follows:

$$
\mathrm{n}=\frac{\partial \ln \dot{\varepsilon}}{\partial \ln [\sinh (\alpha \sigma)]}
$$


The variation of $\ln [\sinh (\alpha \sigma)]$ with $\ln \dot{\varepsilon}$ as shown in Figure $4 \mathrm{a}$. The data points at different temperatures are fitted into a straight line, and the inverse of the slope is the approximate value of $n$ at that temperature. Finding the average of the inverse of the slope of the straight line at different phase region temperature is the value of $n$, as shown in Table 2.

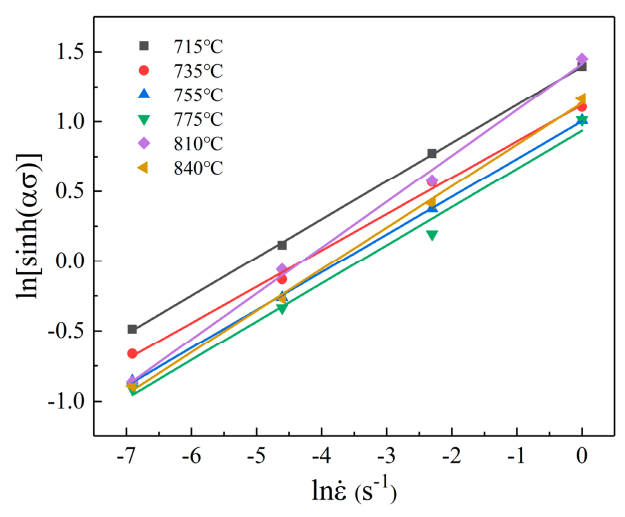

(a)

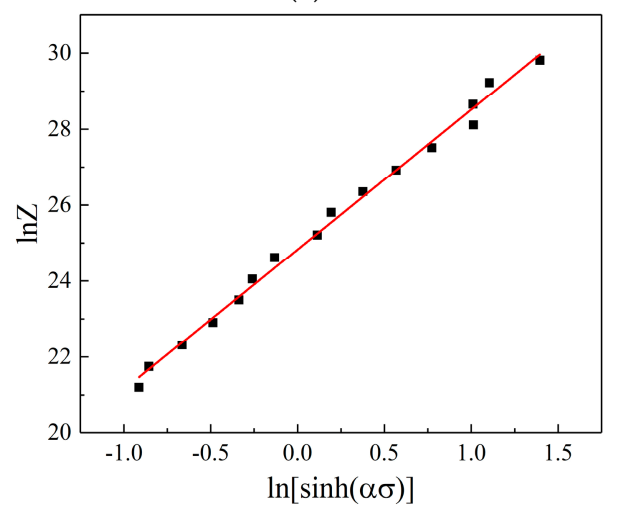

(c)

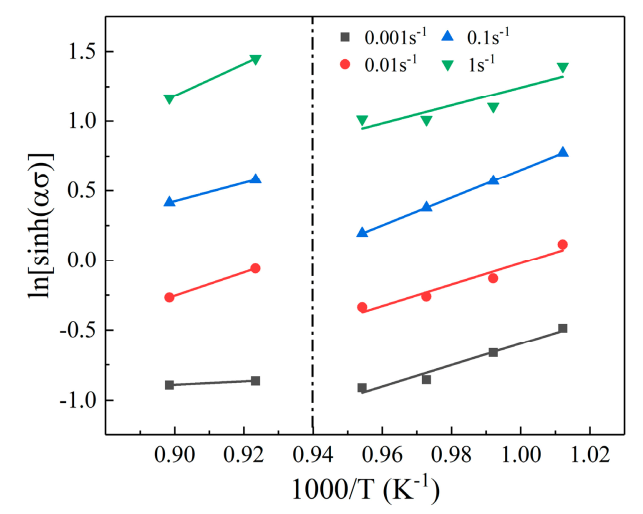

(b)

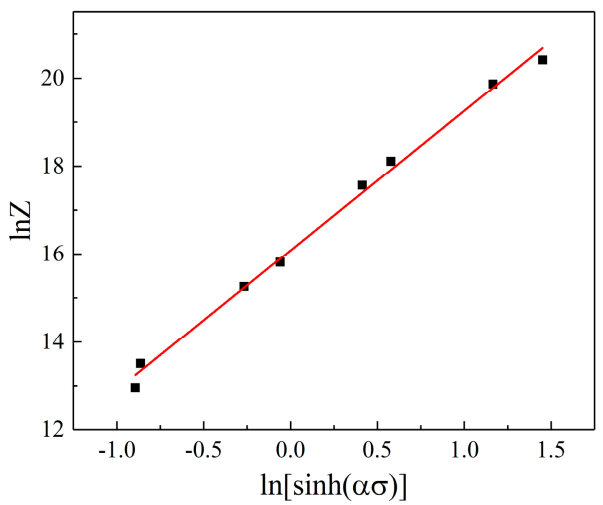

(d)

Figure 4. The relationships of (a); (b) $\ln [\sinh (\alpha \sigma)]$ and $1000 / \mathrm{T}$; (c) $\ln Z$ and $\ln [\sinh (\alpha \sigma)]$ in $\alpha+\beta$ phase; (d) $\ln Z$ and $\ln [\sinh (\alpha \sigma)]$ in $\beta$ phase.

At a given strain rate, solve both sides of Equation (6) for partial differentials about $\mathrm{T}^{-1}$ at the same time, and sort out the following equation:

$$
\mathrm{Q}=\left.\mathrm{nR} \frac{\partial \ln [\sinh (\alpha \sigma)]}{\partial\left(\frac{1}{\mathrm{~T}}\right)}\right|_{\varepsilon, \dot{\varepsilon}}
$$

The theory of plastic deformation believes that the deformation activation energy is an energy barrier that must be overcome in the process of atomic transition of the material during thermal deformation, and it can reflect the difficulty of material deformation. According to Figure $4 \mathrm{~b}, \mathrm{Q}$-value is further determined by the linear fitting of $\ln [\sinh (\alpha \sigma)]$ and $1000 / T$. Table 3 lists the $Q$ values of several typical high strength-toughness titanium alloys during processing in different phase regions. During the $\beta$-phase region deformation, the $Q$ values of all the listed alloys are small, which may be related to the difference in the crystal structure of the $\alpha$-phase and the $\beta$-phase. The $Q$ of the pure titanium $\beta$ phase is $153 \mathrm{KJ} / \mathrm{mol}$, and the $\mathrm{Q}$ of the $\alpha$ phase is $242 \mathrm{KJ} / \mathrm{mol}$ [33]. Under different deformation conditions, the thermal deformation activation energy obtained reflects the thermal deformation mechanism of the material to a certain extent. The $Q$ value of the Ti-6554 alloy when deformed in the $\beta$ phase region is $184 \mathrm{KJ} / \mathrm{mol}$, which is between the $Q$ values of $\alpha$ phase and $\beta$ phase, indicating that the main deformation mechanism may be the DRV caused by dislocation slip and climbing. The $Q$ value during deformation in the $\alpha+\beta$ phase region is $245 \mathrm{KJ} / \mathrm{mol}$, which is slightly 
higher than the pure titanium $\alpha$ phase, indicating that the main deformation mechanism may be dynamic and metastable recrystallization.

Table 3. Activation energy for several typical high strength-toughness titanium alloys.

\begin{tabular}{ccccc}
\hline Alloy & $\begin{array}{c}\text { Transformation Point } \\
\mathbf{T}_{\boldsymbol{\beta}} /{ }^{\circ} \mathbf{C}\end{array}$ & $\begin{array}{c}\text { Deformation } \\
\text { Temperature } \mathbf{T} /{ }^{\circ} \mathbf{C}\end{array}$ & $\begin{array}{c}\text { Strain Rate } \\
\dot{\boldsymbol{\varepsilon}} / \mathbf{s}^{\mathbf{- 1}}\end{array}$ & $\mathbf{Q} / \mathbf{k J} \cdot \mathbf{m o l}^{\mathbf{- 1}}$ \\
\hline \multirow{2}{*}{ Ti-1300 [34] } & 875 & $860 \sim 890$ & $10^{-2} \sim 10$ & 178 \\
& & $800 \sim 860$ & & 216 \\
Ti-55511 [35] & 845 & $850 \sim 950$ & $10^{-3} \sim 10$ & 137 \\
& & $700 \sim 800$ & & 288 \\
Ti-55531 [36] & 803 & $823 \sim 843$ & $10^{-2} \sim 1$ & 148 \\
& & $763 \sim 783$ & & 275 \\
Ti-6554 & 790 & $810 \sim 840$ & $10^{-3} \sim 10$ & 184 \\
& & $715 \sim 775$ & & 245 \\
\hline
\end{tabular}

Substituting Q, n, $\alpha, T$, and $\dot{\varepsilon}$ into Equation (6), the $Z$ values of different thermal deformation parameters can be obtained. As shown in Figure $4 c, d$, draw the relation diagram of $\ln Z-\ln [\sin h(\alpha \sigma)]$ and perform linear fitting with the least square method. The intercept of the line is the value of $\ln A$.

Substitute all the above data into Equation (5), the flow stress model of Ti-6554 alloy under different process parameters can be obtained as follows:

$\alpha+\beta$ two-phase region:

$$
\dot{\varepsilon}=6.06 \times 10^{10}[\sinh (0.006951 \sigma)]^{3.70} \exp \left(-\frac{2.45 \times 10^{5}}{\mathrm{RT}}\right)
$$

$\beta$ single phase region:

$$
\dot{\varepsilon}=9.64 \times 10^{6}[\sinh (0.010223 \sigma)]^{3.20} \exp \left(-\frac{1.84 \times 10^{5}}{\mathrm{RT}}\right)
$$

\subsection{Verification of Different Strain Constitutive Models}

So far, the constitutive equation of a certain true strain of 0.6 has been obtained. However, during thermal deformation of metallic materials, the effect of strain on flow stress is very obvious, so in order to describe the flow stress of materials more accurately, it is necessary to verify the constitutive model under different strains. Hence, the material constants $(a, \ln A, n, Q)$ corresponding to different strains can be obtained by the above method. Then select Equations (10)-(13) to perform fifth-order polynomial regression on the four material constants. The polynomial fitting curves of the material constants to the true-stress as depicted in Figure 5. The polynomial fitting results are shown in Tables 4 and 5 .

$$
\begin{gathered}
\alpha=\mathrm{X}_{0}+\mathrm{X}_{1} \varepsilon+\mathrm{X}_{2} \varepsilon^{2}+\mathrm{X}_{3} \varepsilon^{3}+\mathrm{X}_{4} \varepsilon^{4}+\mathrm{X}_{5} \varepsilon^{5} \\
\mathrm{n}=\mathrm{N}_{0}+\mathrm{N}_{1} \varepsilon+\mathrm{N}_{2} \varepsilon^{2}+\mathrm{N}_{3} \varepsilon^{3}+\mathrm{N}_{4} \varepsilon^{4}+\mathrm{N}_{5} \varepsilon^{5} \\
\mathrm{Q}=\mathrm{Q}_{0}+\mathrm{Q}_{1} \varepsilon+\mathrm{Q}_{2} \varepsilon^{2}+\mathrm{Q}_{3} \varepsilon^{3}+\mathrm{Q}_{4} \varepsilon^{4}+\mathrm{Q}_{5} \varepsilon^{5} \\
\ln \mathrm{A}=\mathrm{Y}_{0}+\mathrm{Y}_{1} \varepsilon+\mathrm{Y}_{2} \varepsilon^{2}+\mathrm{Y}_{3} \varepsilon^{3}+\mathrm{Y}_{4} \varepsilon^{4}+\mathrm{Y}_{5} \varepsilon^{5}
\end{gathered}
$$

Through the above method, we can build constitutive models under different strains. In order to verify the reliability of the established Arrhenius constitutive model, as shown in Figure 6, the model calculated stress value is compared with the experimentally stress value. The observation shows that the deviation between the theoretical value and the measured value is not large, which indicates that the established Arrhenius model is reliable. To further quantitatively test the accuracy of the proposed 
stress constitutive model of Ti-6554 alloy, the correlation coefficient $\mathrm{R}$ and the average absolute relative error (AARE) are used to estimate the model accuracy. The mathematical expression is as follows:

$$
\begin{gathered}
\mathrm{R}=\frac{\sum_{\mathrm{i}=1}^{\mathrm{N}}\left(\mathrm{E}_{\mathrm{i}}-\overline{\mathrm{E}}\right)\left(\mathrm{P}_{\mathrm{i}}-\overline{\mathrm{P}}\right)}{\sqrt{\sum_{\mathrm{i}=1}^{\mathrm{N}}\left(\mathrm{E}_{\mathrm{i}}-\overline{\mathrm{E}}\right)^{2} \sum_{\mathrm{i}=1}^{\mathrm{N}}\left(\mathrm{P}_{\mathrm{i}}-\overline{\mathrm{P}}\right)^{2}}} \\
\operatorname{AARE}(\%)=\frac{1}{\mathrm{~N}} \sum_{\mathrm{i}=1}^{\mathrm{N}}\left|\frac{\mathrm{E}_{\mathrm{i}}-\mathrm{P}_{\mathrm{i}}}{\mathrm{E}_{\mathrm{i}}}\right| \times 100
\end{gathered}
$$

where $E_{i}$ is the measured stress, $P_{i}$ is the model calculated stress, $\bar{E}$ is the measured stress average. As shown in Figure 7, the values of $R$ and AARE are 0.994 and 3.80\%, respectively. This indicated that the established constitutive model has good precision. From the above qualitative and quantitative analysis, it can be seen that the constitutive model proposed in this study can accurately reflect the stress characteristics of Ti-6554 alloy, and has good precision, thus verifying the reliability of the model.

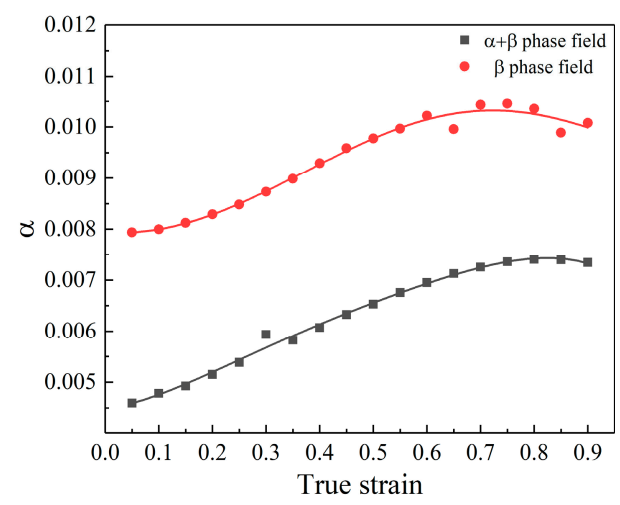

(a)

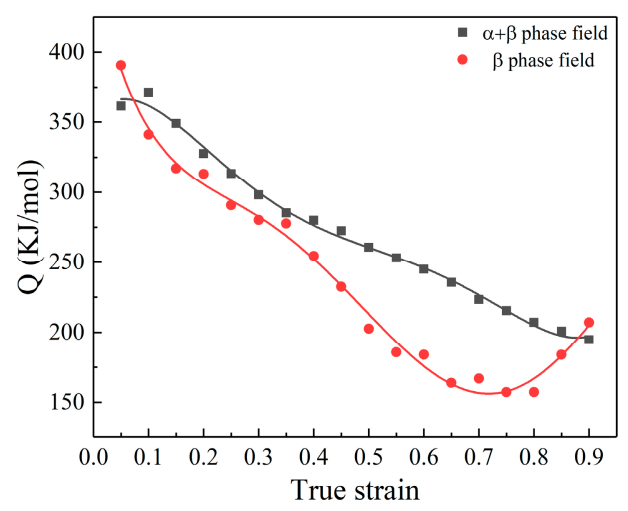

(c)

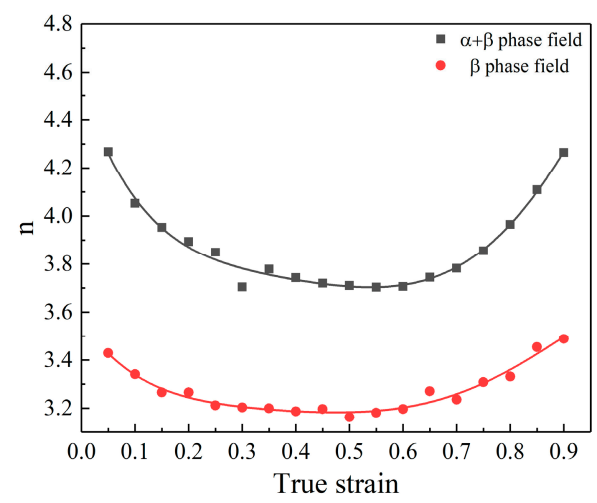

(b)

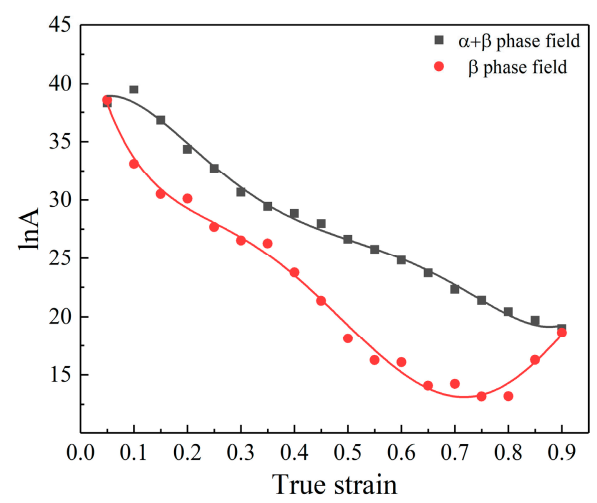

(d)

Figure 5. The fitted curves of (a) $\alpha ;(\mathbf{b}) \mathrm{n} ;(\mathbf{c}) \mathrm{Q} ;$ (d) $\ln \mathrm{A}$.

\begin{tabular}{|c|c|c|c|c|c|c|c|}
\hline \multicolumn{2}{|c|}{$\alpha$} & \multicolumn{2}{|c|}{$\mathrm{n}$} & \multicolumn{2}{|r|}{$\mathbf{Q}$} & \multicolumn{2}{|r|}{$\ln A$} \\
\hline $\mathrm{X}_{0}$ & 0.00449 & $\mathrm{~N}_{0}$ & 4.53506 & $\mathrm{Q}_{0}$ & 356.55303 & $\mathrm{Y}_{0}$ & 37.73193 \\
\hline$x_{1}$ & 0.00117 & $\mathrm{~N}_{1}$ & -6.57274 & $\mathrm{Q}_{1}$ & 390.72639 & $\mathrm{Y}_{1}$ & 46.276 \\
\hline$x_{2}$ & 0.01945 & $\mathrm{~N}_{2}$ & 23.81874 & $\mathrm{Q}_{2}$ & -4473.36504 & $\mathrm{Y}_{2}$ & -531.88745 \\
\hline$x_{3}$ & -0.04781 & $\mathrm{~N}_{3}$ & -45.73538 & $\mathrm{Q}_{3}$ & 12113.23612 & $\mathrm{Y}_{3}$ & 1449.71709 \\
\hline$X_{4}$ & 0.05363 & $\mathrm{~N}_{4}$ & 42.39728 & $\mathrm{Q}_{4}$ & -13845.55598 & $\mathrm{Y}_{4}$ & -1663.14237 \\
\hline$X_{5}$ & -0.02422 & $\mathrm{~N}_{5}$ & -13.74889 & $\hat{\mathrm{Q}}_{5}$ & 5700.25554 & $\mathrm{Y}_{5}$ & 685.98485 \\
\hline
\end{tabular}

Table 4. Polynomial fitting results of $a, \ln A, n, Q$ in $\alpha+\beta$ phase region. 
Table 5. Polynomial fitting results of $a, \ln A, n, Q$ in $\beta$ phase region.

\begin{tabular}{cccccccc}
\hline & $\alpha$ & & $\mathbf{n}$ & & $\mathbf{Q}$ & & $\ln \mathbf{A}$ \\
\hline $\mathrm{X}_{0}$ & 0.00794 & $\mathrm{~N}_{0}$ & 3.56092 & $\mathrm{Q}_{0}$ & 457.62985 & $\mathrm{Y}_{0}$ & 42.82754 \\
$\mathrm{X}_{1}$ & -0.000679 & $\mathrm{~N}_{1}$ & -3.21573 & $\mathrm{Q}_{1}$ & -1759.56953 & $\mathrm{Y}_{1}$ & -191.89453 \\
$\mathrm{X}_{2}$ & 0.01243 & $\mathrm{~N}_{2}$ & 12.24894 & $\mathrm{Q}_{2}$ & 8148.57959 & $\mathrm{Y}_{2}$ & 890.00338 \\
$\mathrm{X}_{3}$ & 0.00287 & $\mathrm{~N}_{3}$ & -25.02692 & $\mathrm{Q}_{3}$ & -19516.71413 & $\mathrm{Y}_{3}$ & -2131.70623 \\
$\mathrm{X}_{4}$ & -0.2847 & $\mathrm{~N}_{4}$ & 25.43849 & $\mathrm{Q}_{4}$ & 20285.7594 & $\mathrm{Y}_{4}$ & 2216.20461 \\
$\mathrm{X}_{5}$ & 0.01556 & $\mathrm{~N}_{5}$ & -9.37857 & $\mathrm{Q}_{5}$ & -7368.92828 & $\mathrm{Y}_{5}$ & -805.47528 \\
\hline
\end{tabular}

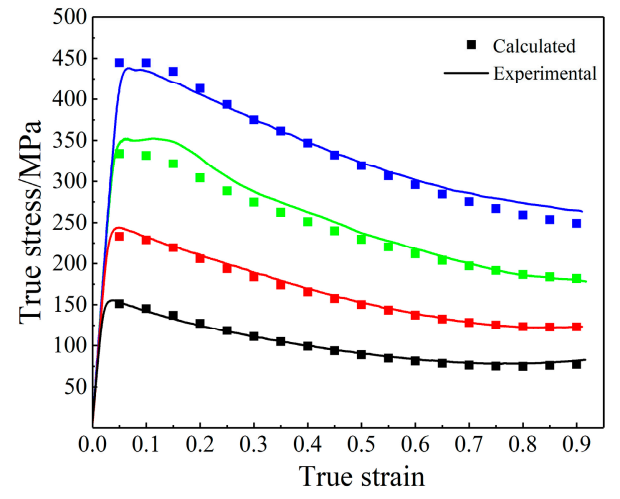

(a)

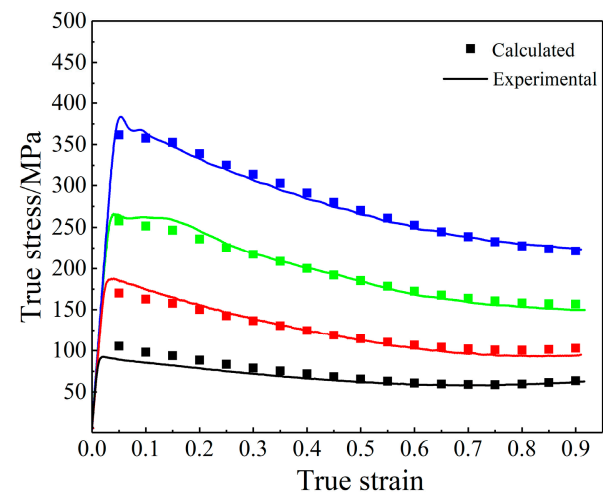

(c)

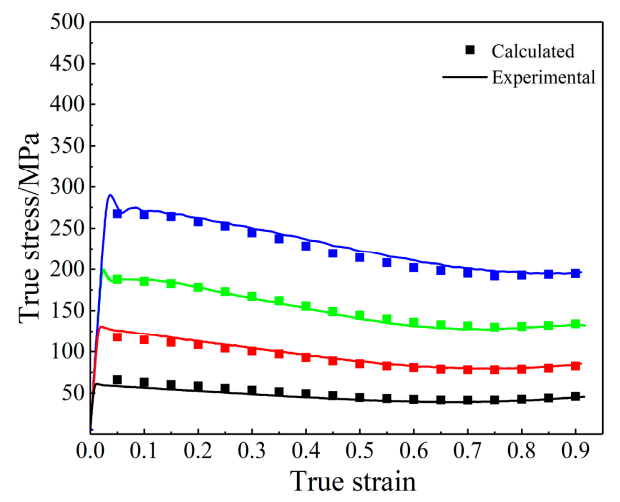

(e)

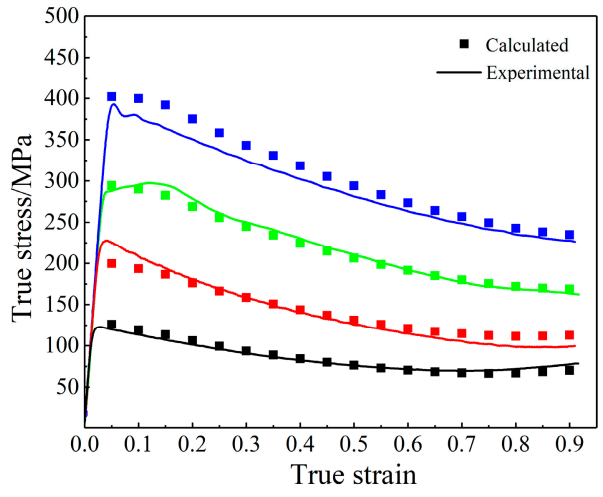

(b)

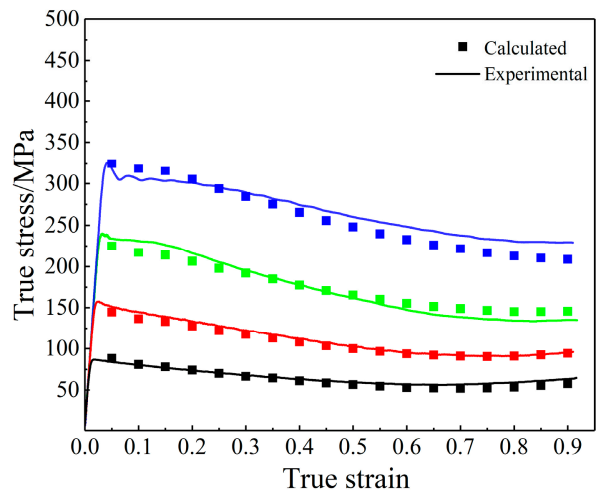

(d)

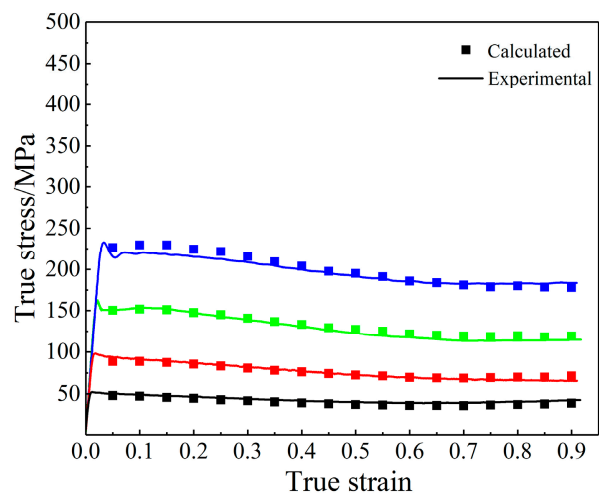

(f)

Figure 6. Comparison between experimental and model calculated flow stress at deformation temperatures of (a) $715^{\circ} \mathrm{C}$; (b) $735^{\circ} \mathrm{C}$; (c) $755^{\circ} \mathrm{C}$; (d) $775^{\circ} \mathrm{C}$; (e) $810{ }^{\circ} \mathrm{C}$; (f) $840{ }^{\circ} \mathrm{C}$. 


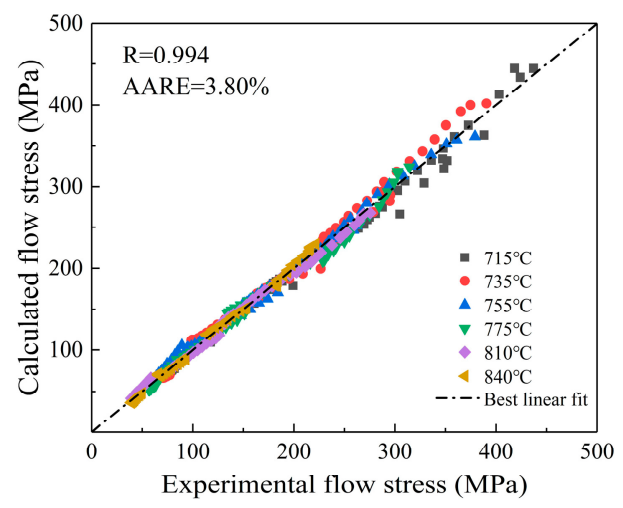

Figure 7. Correlations between experimental and model calculated flow stress.

\subsection{Establishment of Processing Map}

The processing map is mainly established through the DMM proposed by Prasad and Gegel [37]. It can evaluate the processing performance of metal materials and optimize the process parameters, and can achieve the role of controlling product performance and microstructure evolution. According to the DMM, the workpiece undergoing thermal deformation is a non-linear power dissipation unit, and the power input $\mathrm{P}$ of the workpiece during the hot forming process can be divided into two parts: dissipation content $(\mathrm{G})$ and dissipation co-content $(\mathrm{J})$, as follows:

$$
\mathrm{P}=\sigma \dot{\varepsilon}=\mathrm{G}+\mathrm{J}=\int_{0}^{\dot{\varepsilon}} \sigma \mathrm{d} \dot{\varepsilon}+\int_{0}^{\sigma} \dot{\varepsilon} \mathrm{d} \sigma
$$

Dissipation content $(\mathrm{G})$ refers to the power dissipated during thermal deformation, and most of the dissipation is converted into thermal energy, and a small part is stored in the workpiece; dissipation co-content $(\mathrm{J})$ refers to the power consumed in the process of microstructure evolution during thermal deformation of materials, which is finally released as thermal energy. The distribution relationship of the total input power $\mathrm{P}$ between the dissipation content $\mathrm{G}$ and dissipation co-content $\mathrm{J}$ is determined by strain rate sensitivity index $(\mathrm{m})$, as follows:

$$
\mathrm{m}=\frac{\partial \mathrm{J}}{\partial \mathrm{G}}=\frac{\dot{\varepsilon} \partial \sigma}{\sigma \partial \dot{\varepsilon}}=\frac{\partial \ln \sigma}{\partial \ln \dot{\varepsilon}}
$$

For an ideal linear dissipative unit, the $\mathrm{m}$ value is 1 , and $\mathrm{J}$ has a maximum value $\mathrm{J}=\mathrm{J}_{\max }=\frac{\sigma \dot{\varepsilon}}{2}$. For the nonlinear dissipation process, the power dissipation efficiency $\eta$ can be used to describe the efficiency of the energy consumed by microstructural changes during plastic deformation, which is shown as the following:

$$
\eta=\frac{\mathrm{J}}{\mathrm{J}_{\max }}=\frac{2 \mathrm{~m}}{\mathrm{~m}+1}
$$

By calculating the value of $\eta$, the power dissipation maps under different hot deformation conditions can be obtained. Generally, the power dissipation efficiency is proportional to the deformation mechanism, the higher the value of $\eta$, the better the deformation mechanism. In order to deal with the deformation instability of materials during hot working, Prasad et al. [38] proposed an instability criterion that can distinguish the thermal deformation instability region from the stability region of materials. The conditions of deformation instability of materials are as follows:

$$
\xi(\dot{\varepsilon})=\frac{\partial \ln \left(\frac{m}{m+1}\right)}{\partial \ln \dot{\varepsilon}}+\mathrm{m}<0
$$


The region with a negative parameter $\xi(\dot{\varepsilon})$ is the instability region, which is the processing risk region, and may produce adiabatic shear band, crack, mechanical twinning, and so on. By changing the instability criterion, the instability maps of the material can be drawn, and the processing maps of the material can be obtained by superposing the instability maps with the power dissipation maps. Based on the above method, the power dissipation maps under different strains are shown in Figure 8. It can be seen from Figure 8 that the peak value of power dissipation efficiency of the alloy varies greatly under different strains, and the peak value of power dissipation efficiency decreases with the increase of strain. When the strain is 0.3 , at the deformation temperature of $790-840{ }^{\circ} \mathrm{C}$ and the strain is less than $0.01 \mathrm{~s}^{-1}$, the peak power dissipation efficiency can reach 0.56 , which indicates that the better microstructure can be obtained by hot working in this range. With the increase of strain, the peak area of power dissipation efficiency is concentrated in the deformation temperature of $800-830^{\circ} \mathrm{C}$, and the strain rate is $0.01-0.001 \mathrm{~s}^{-1}$, which indicates that this range is the better processing parameter range of Ti-6554 alloy. At this time, the material's DRX is more sufficient, the microstructure is fine, and it has good mechanical properties. Conversely, the shaded area in the processing maps (as shown in Figure 9) shows the characteristic of instability. The instability region is basically the same under different strains, mainly concentrated in the low temperature $\left(715-750^{\circ} \mathrm{C}\right)$ and high strain rate $\left(0.1-1 \mathrm{~s}^{-1}\right)$ area. However, when the strain reached 0.9 , a small part of the instability region was added near the medium temperature $\left(770-795^{\circ} \mathrm{C}\right)$ and high strain rate $\left(0.001-0.003 \mathrm{~s}^{-1}\right)$ region. Therefore, in the process of hot working, processing in these regions should be avoided, otherwise it will lead to uneven distribution of material structure, crack, and mechanical property decline, which will seriously deteriorate the mechanical properties of the material.

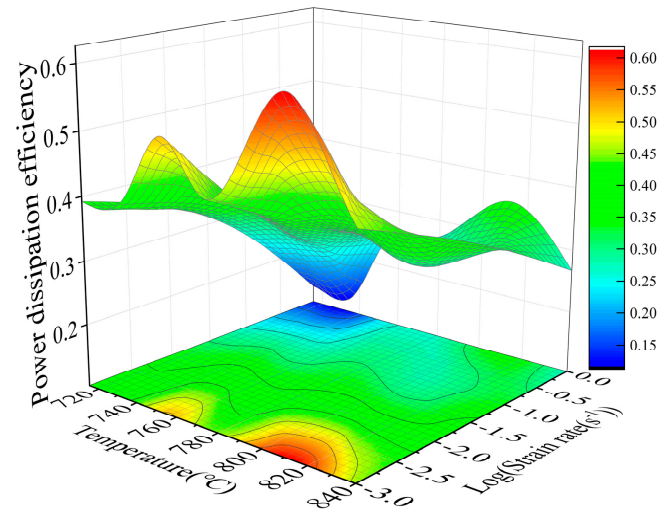

(a)

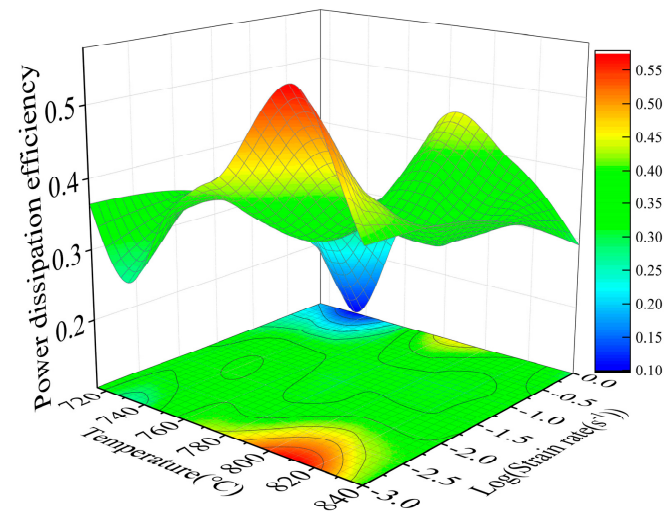

(b)

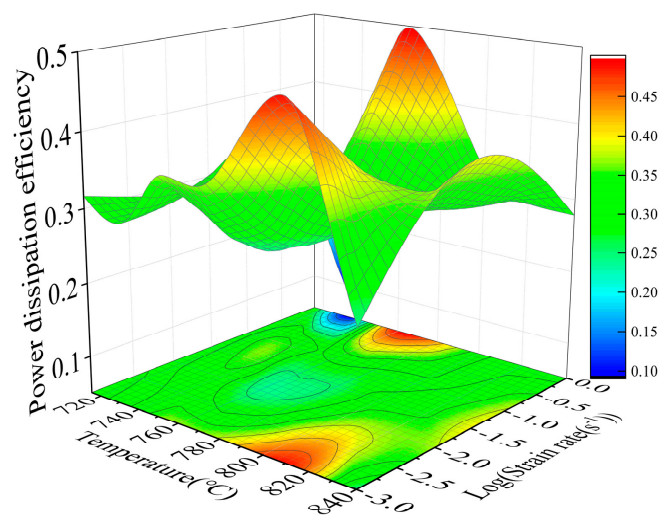

(c)

Figure 8. The power dissipation map of Ti-6554 alloy at the true strain of: (a) 0.3 ; (b) 0.6 ; (c) 0.9 . 


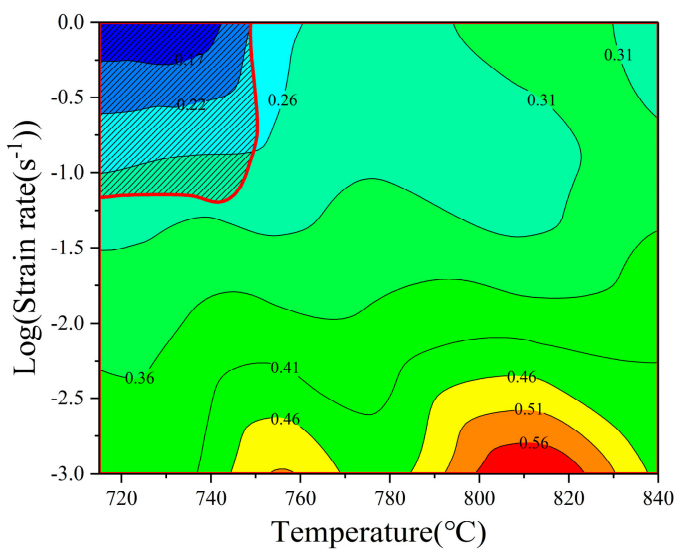

(a)

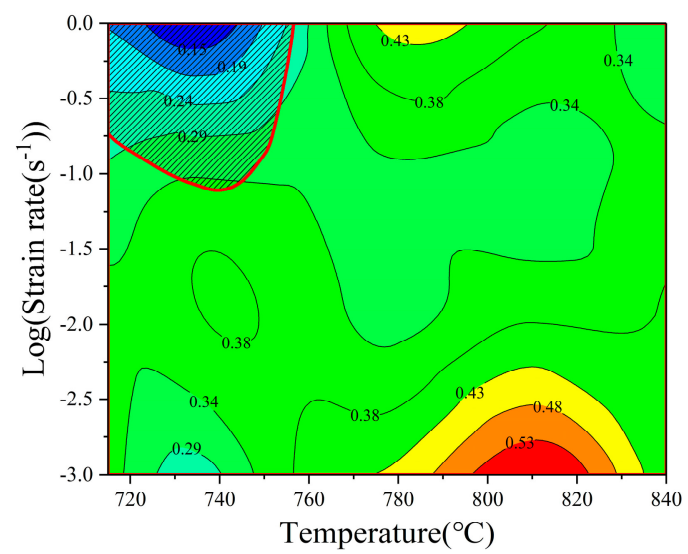

(b)

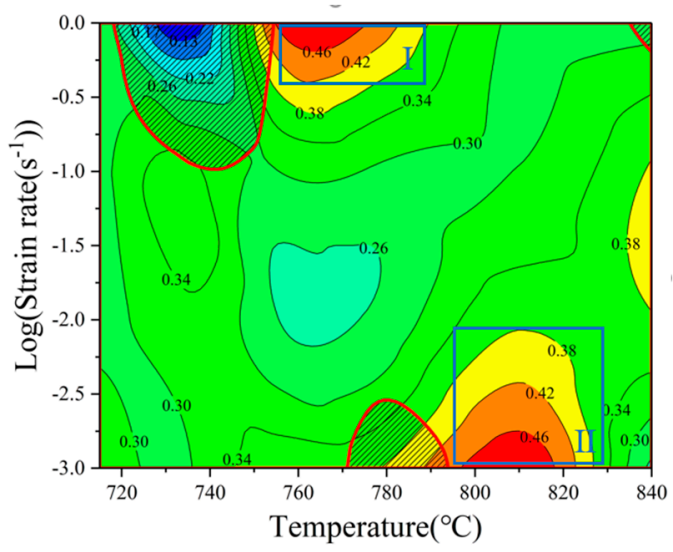

(c)

Figure 9. Processing maps of Ti-6554 alloy at the true strain of: (a) 0.3 ; (b) 0.6 ; (c) 0.9 .

As shown in Figure 9c, when the true strain is 0.9 , the stable deformation region is composed of two regions: domain I with the deformation temperatures of $760-790{ }^{\circ} \mathrm{C}$ and strain rates of $0.178-1 \mathrm{~s}^{-1}$, the $\eta$-value is $0.34-0.46$; domain II with the deformation temperatures of $800-830{ }^{\circ} \mathrm{C}$ and strain rates of $0.001-0.01 \mathrm{~s}^{-1}$, the $\eta$-value is $0.38-0.46$. However, the range of effective deformation temperature and strain rate in domain I is narrow, which is not conducive to large-scale processing of the alloy. Therefore, the optimal hot processing area determined by the processing map are the deformation temperatures of $800-830{ }^{\circ} \mathrm{C}$ and the strain rates of $0.001-0.01 \mathrm{~s}^{-1}$. The following shows a typical microstructure of instability region and safety region, as shown in Figure 10. Among them, Figure 10a shows the microstructure in the instability area. It can be seen from the figure that the $\alpha$ phase is elongated along the direction perpendicular to the compression direction, and the aspect ratio of some $\alpha$ phases reaches 10:1, which is easy to be broken into fine $\alpha$ phase. Moreover, due to the high strain rate, the center area of the alloy is prone to a large temperature rise effect, and the thermal conductivity of Ti6554 alloy is poor, which is easy to cause unstable tissue properties. Figure $10 \mathrm{~b}$ shows the microstructure in the safety area, mainly composed of $\beta$ grains, and contains a small amount of equiaxed $\beta$ grains, indicating that DRX has occurred under this condition, and the alloy has better overall performance.

Through the above analysis, we have determined the hot workability of the alloy for an area of temperatures and strain rates. During the forging process of the titanium alloy in the cross-phase region, since forging needs to be performed in different phase regions, it is particularly important to ensure that the hot processing process parameters selected in the different phase regions are not in the instability region. According to the processing maps, we can determine the better cross-phase forging process parameters: in the $\beta$ single-phase region, the forging temperatures of $800-830{ }^{\circ} \mathrm{C}$ and the strain rates of $0.001-0.01 \mathrm{~s}^{-1}$; in the $\alpha+\beta$ phase region, the forging temperatures of $740-765^{\circ} \mathrm{C}$ and the strain 
rates of $0.001-0.01 \mathrm{~s}^{-1}$. The distribution of the deformation of different phase regions in the cross-phase forging can also be determined by reference to the processing maps. Therefore, the processing maps can be used to guide the cross-phase forging and provide reference for determining the best cross-phase forging process parameters.

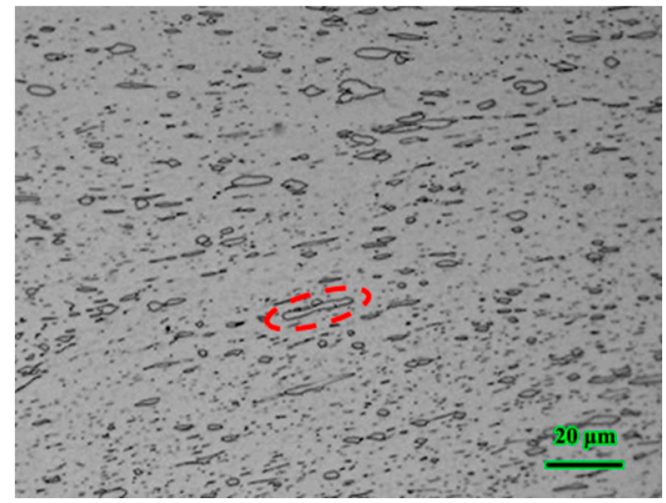

(a)

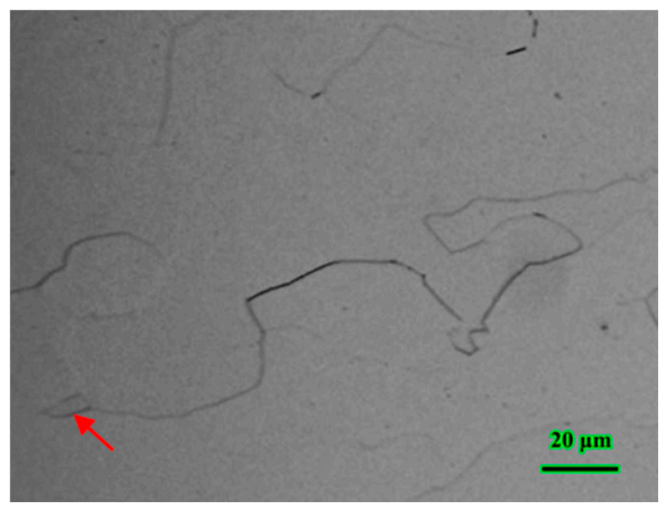

(b)

Figure 10. Typical microstructure of instability region and safety region. (a) $735{ }^{\circ} \mathrm{C} / 1 \mathrm{~s}^{-1}$; (b) $810^{\circ} \mathrm{C} / 0.001 \mathrm{~s}^{-1}$.

\subsection{Microstructure Evolution}

Figure 11 shows the microstructure of Ti-6554 alloy after a $60 \%$ thermal deformation at different deformation temperatures under the condition of strain rate $0.001 \mathrm{~s}^{-1}$. During thermal deformation below the phase transition point $\left(790^{\circ} \mathrm{C}\right)$, the deformed structure is mainly composed of equiaxed $\alpha$ phases evenly distributed on the $\beta$ matrix. As shown in Figure 11a,b, when the deformation temperature rises from $715^{\circ} \mathrm{C}$ to $735^{\circ} \mathrm{C}$, the shape of the primary $\alpha$ phase is equiaxed, and the volume fraction and size of the primary $\alpha$ phase does not change much. When the deformation temperature rises to $755^{\circ} \mathrm{C}$, as shown in Figure $11 \mathrm{c}$, the shape of the primary $\alpha$ phase is basically unchanged, but its volume fraction and size decrease. When the deformation temperature reaches $775{ }^{\circ} \mathrm{C}$, as shown in Figure $11 d$, the equiaxed $\alpha$ phase gradually dissolves, and its volume fraction and size decrease amplitude increases. This is because the higher the deformation temperature, the greater the degree of transformation of the $\alpha$ phase into the $\beta$ phase within the alloy. On the other hand, as the deformation temperature increases, the $\alpha$ phase will swallow the surrounding fine $\alpha$ phase, thereby increasing the size of the $\alpha$ phase. During the thermal deformation of the alloy, these two mechanisms coexist, but when the temperature rises to a certain level, the former mechanism dominates, resulting in a rapid decline in the volume fraction and size of the primary $\alpha$ phase. Below the phase change point, the general change trend is as the deformation temperature increases, the volume fraction and size of the primary $\alpha$ phase in the microstructure of Ti-6554 alloy decrease simultaneously.

During thermal deformation above the phase transition point, the $\alpha$ phase in the microstructure is completely dissolved and the microstructure of the alloy consists mainly of flattened $\beta$ grains, as depicted in Figure 11e,f. At this point, the $\beta$ grain is severely deformed, elongated, and forms distinct streamlines, the grain boundary is large serrated, and a small amount of relatively small equiaxed $\beta$ grains are observed around the flattened $\beta$ grain. Among them, the flattened $\beta$ grains are the remains of the original microstructure, while the equiaxed $\beta$ grains are the new grains produced by dynamic recrystallization.

Above the phase transition point, with the deformation temperature increases, the $\beta$ grain grows gradually, and the bending effect of grain boundary is more obvious. This is because: on the one hand, at higher temperatures, the ability of atoms to move is enhanced due to thermal activation, the faster the atom diffusion rate, the faster the migration rate, the smaller the hindrance effect of defects such as vacancy on dislocation, and the enhanced grain boundary slip ability. On the other 
hand, as the temperature increases, the large $\beta$ grains are more likely to swallow the small $\beta$ grains, resulting in the $\beta$ grain coarsening. At the same time, although with the deformation temperature increases, the ability of atom migration and diffusion is stronger, the occurrence of DRV in Ti-6554 alloy reduces the distortion energy, thus reducing the driving force of DRX nucleation, but the high temperature promotes the growth of recrystallized grains, which makes the size of DRX grains larger and the volume fraction increased.

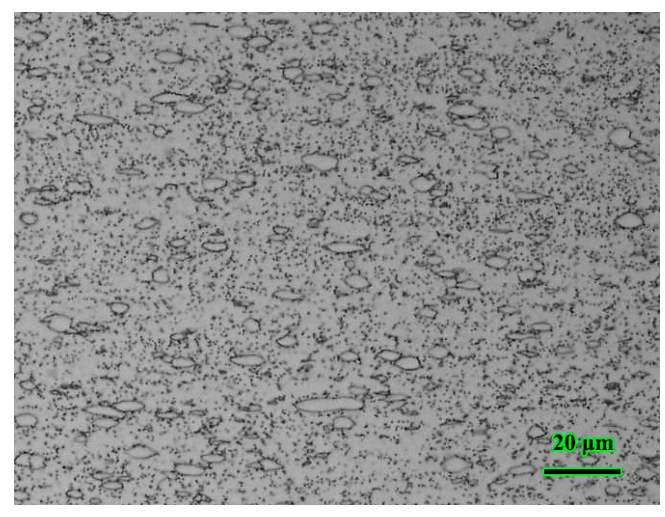

(a)

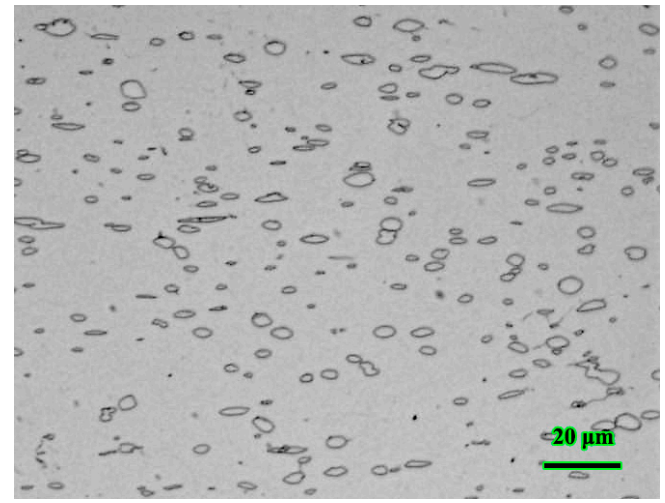

(c)

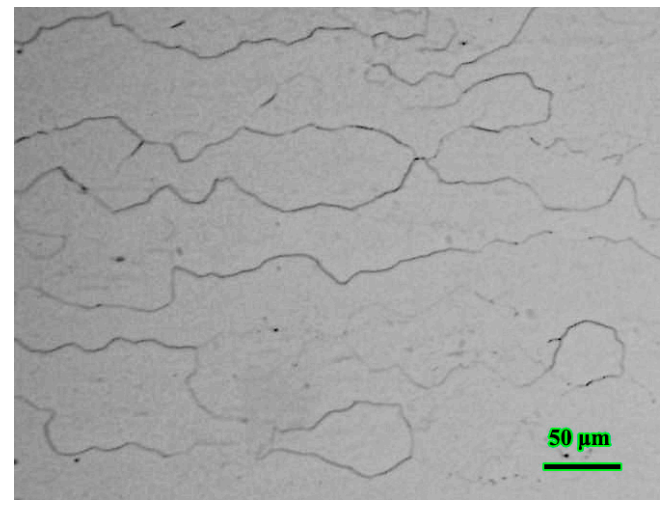

(e)

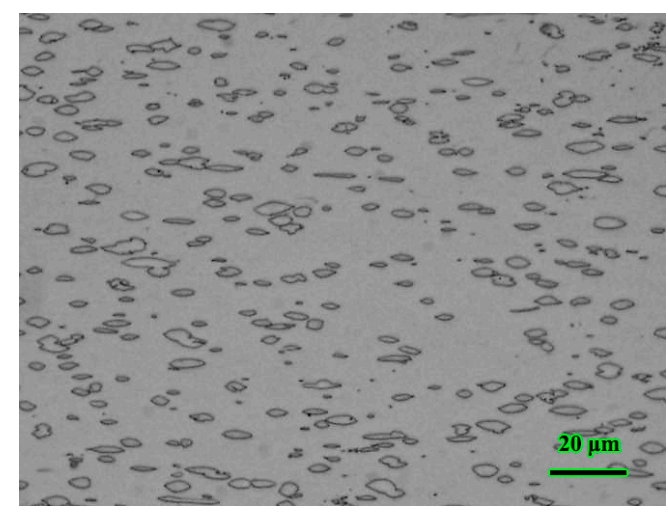

(b)

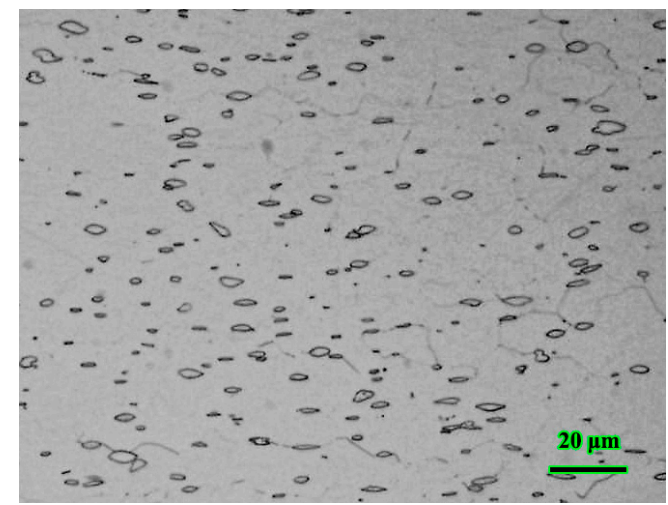

(d)

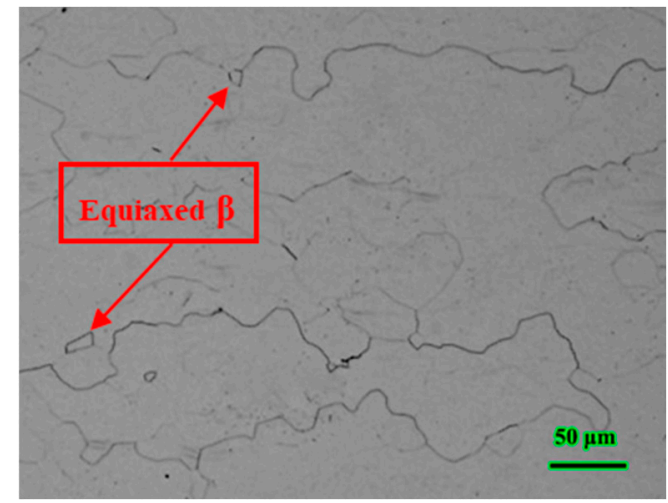

(f)

Figure 11. The microstructure of different deformation temperatures at $0.001 \mathrm{~s}^{-1}$ : (a) $715{ }^{\circ} \mathrm{C}$; (b) $735{ }^{\circ} \mathrm{C}$; (c) $755{ }^{\circ} \mathrm{C}$; (d) $775{ }^{\circ} \mathrm{C}$; (e) $810{ }^{\circ} \mathrm{C}$; (f) $840{ }^{\circ} \mathrm{C}$.

Figure 12 shows the microstructures of Ti-6554 titanium alloy in single phase region after hot deformation. According to Figure 12a,b, when the strain rates were $0.001 \mathrm{~s}^{-1}$ and $0.1 \mathrm{~s}^{-1}$, the $\beta$ grain boundary is relatively curved, and some of the $\beta$ grains present an equiaxed shape. This is because with the acceleration of strain, the deformation duration is shortened, the mechanisms of grain boundary sliding and diffusion creep are gradually replaced by dislocation movement, and the shape 
of the grain changes into a band. At a low strain rate, the dynamic recovery consumes only a small amount of dislocations in the alloy grain, resulting in a large distortion energy. The driving force of dynamic recrystallization is large, so there are many nucleation points and a relatively large amount of recrystallization. The softening mechanism inside the alloy is mainly DRX.

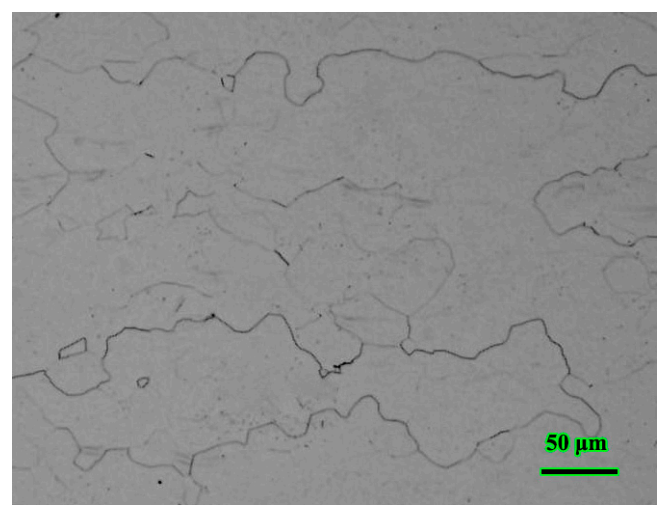

(a)

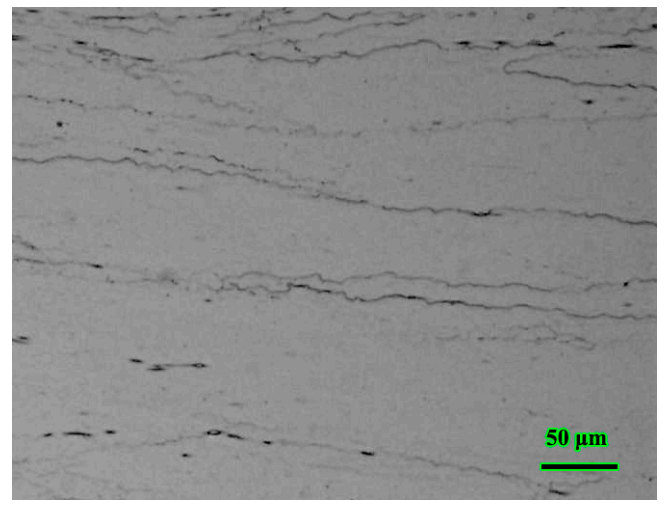

(c)

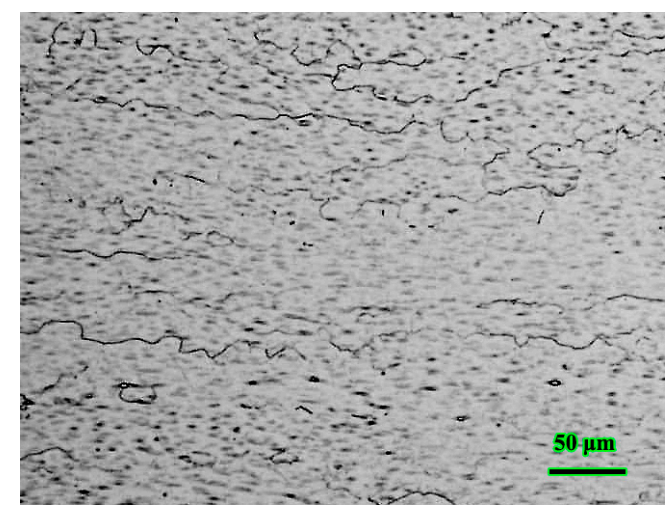

(b)

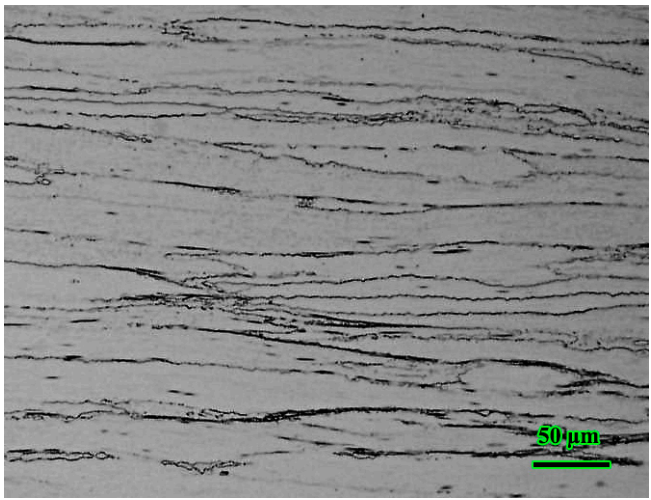

(d)

Figure 12. The microstructure of different strain rate at $840{ }^{\circ} \mathrm{C}$ : (a) $0.001 \mathrm{~s}^{-1}$; (b) $0.01 \mathrm{~s}^{-1}$; (c) $0.1 \mathrm{~s}^{-1} ;(\mathbf{d}) 1 \mathrm{~s}^{-1}$.

However, under the higher strain rate $\left(0.1 \mathrm{~s}^{-1}, 1 \mathrm{~s}^{-1}\right)$, it can be observed from Figure $12 \mathrm{c}, \mathrm{d}$ that $\beta$ grains are seriously elongated and strip like. The $\beta$ grain boundary is relatively smooth, has a fine zigzag shape, and no recrystallized grains appear. When the strain rate is high, the deformation time is shortened, the atom has no time to diffuse, the grain boundary slip and diffusion creep are difficult, and the cross slip has no time to complete, the dislocation density increases rapidly in a short time, resulting in dislocation entanglement, and the softening mechanism in the alloy is mainly dynamic recovery. By means of dynamic recovery and local migration of grain boundaries, the surface tension of grain boundaries can reach a dynamic balance with the ever-changing dislocation density, thus forming a fine jagged grain boundary [39].

\section{Conclusions}

In this study, the thermal deformation behavior of Ti-6554 alloy under the deformation temperatures of $715-840{ }^{\circ} \mathrm{C}$ and the strain rates of $0.001 \mathrm{~s}^{-1}-1 \mathrm{~s}^{-1}$ was studied by thermal simulation compression test. Some important conclusions are summarized as follows:

(1) The flow stress is sensitive to the technological parameters of thermal deformation. The flow stress and peak stress increased with the increase of strain rate. At the same strain rates, the strain required for the stress to reach the peak point is smaller with the temperature increases. 
(2) The constitutive equations of Ti-6554 alloy in different phase regions were established, respectively. $\alpha+\beta$ two-phase region:

$$
\dot{\varepsilon}=6.06 \times 10^{10}[\sinh (0.006951 \sigma)]^{3.70} \exp \left(-\frac{2.45 \times 10^{5}}{\mathrm{RT}}\right)
$$

$\beta$ single-phase region:

$$
\dot{\varepsilon}=9.64 \times 10^{6}[\sinh (0.010223 \sigma)]^{3.20} \exp \left(-\frac{1.84 \times 10^{5}}{\mathrm{RT}}\right)
$$

(3) According to the processing maps, the best range of hot working process parameters were determined as follows: the deformation temperature range of $800-830^{\circ} \mathrm{C}$, the strain rate range of $0.001-0.01 \mathrm{~s}^{-1}$.

(4) Below the phase transition point, with the deformation temperature increases, the volume fraction and size of primary $\alpha$ phase gradually decrease due to the gradual isomeric transformation of primary $\alpha$ phase.

(5) Above the phase transition point, with the deformation temperature increases, $\beta$ grains grow up gradually, and the grain boundary bending effect is more obvious. With the increase of strain rate, the $\beta$ grains deformation becomes more serious, and grain boundary changes from big ripple shape to fine zigzag shape. Dynamic recrystallization mechanism is gradually replaced by dynamic recovery mechanism.

Author Contributions: Methodology, Q.L.; investigation, Q.L. and H.Y.; validation, Y.N.; writing—original draft preparation, Q.L. and Z.W.; writing-reviewing and editing, Y.N.; funding acquisition, Y.N. All authors have read and agreed to the published version of the manuscript.

Funding: This work was supported by the National Natural Science Foundation of China [Grant No. 51775440] and the National Key Research and Development Program of China.

Conflicts of Interest: The authors declare no conflict of interest.

\section{References}

1. Xiao, J.F.; Nie, Z.H.; Tan, C.W.; Zhou, G.; Chen, R.; Li, M.R.; Yu, X.D.; Zhao, X.C.; Hui, S.X.; Ye, W.J.; et al. The dynamic response of the metastable $\beta$ titanium alloy Ti-2Al-9.2Mo-2Fe at ambient temperature. Mater. Sci. Eng. A 2019, 751, 191-200. [CrossRef]

2. Zhao, Q.Y.; Yang, F.; Torrens, R.; Bolzoni, L. Evaluation of the hot workability and deformation mechanisms for a metastable beta titanium alloy prepared from powder. Mater. Charact. 2019, 146, 226-238. [CrossRef]

3. Fan, J.; Li, J.; Li, J.S.; Zhang, Y.D.; Kou, H.C.; Germain, L.; Esling, C. Formation and crystallography of nano/ultrafine-trimorphic structure in metastable $\beta$ titanium alloy Ti-5Al-5Mo-5V-3Cr-0.5Fe processed by dynamic deformation at low temperature. Mater. Charact. 2017, 130, 149-155. [CrossRef]

4. Banerjee, D.; Williams, J.C. Perspective on Titanium science and technology. Acta. Mater. 2013, 61, 844-879. [CrossRef]

5. Long, S.; Xia, Y.F.; Wang, P.; Zhou, Y.T.; Gong, F.J.; Zhou, J.; Zhang, J.S.; Cui, M.L. Constitutive modelling, dynamic globularization behavior and processing map for Ti-6Cr-5Mo-5V-4Al alloy during hot deformation. J. Alloys Compd. 2015, 796, 65-76. [CrossRef]

6. Li, C.L.; Mi, X.J.; Ye, W.J.; Hui, S.X.; Yu, Y.; Wang, W.Q. Effect of solution temperature on microstructures and tensile properties of high strength Ti-6Cr-5Mo-5V-4Al alloy. Mater. Sci. Eng. A 2013, 578, 103-109. [CrossRef]

7. Kumar, J.; Singh, V.; Ghosal, P.; Kumar, V. Characterization of fracture and deformation mechanism in a high strength beta titanium alloy Ti-10-2-3 using EBSD technique. Mater. Sci. Eng. A 2015, 623, 49-58. [CrossRef]

8. Wang, W.Q.; Yang, Y.L.; Zhang, Y.Q.; Li, F.L.; Yang, H.L.; Zhang, P.H. The microstructure and mechanical properties of high-strength and high-toughness titanium alloy BTi-6554 bar. Mater. Sci. Forum 2009, 618-619, 173-176. [CrossRef]

9. Boyer, R.R.; Briggs, R.D. The use of $\beta$ titanium alloys in the aerospace industry. J. Mater. Eng. Perform. 2005, 14, 681-685. [CrossRef] 
10. Zhan, H.; Kent, D.; Wang, G.; Wang, G.; Dargusch, M. The dynamic response of a $\beta$ titanium alloy to high strain rates and elevated temperatures. Mater. Sci. Eng. A 2014,607, 417-426. [CrossRef]

11. Zhan, H.; Zeng, W.; Wang, G.; Kent, D.; Dargusch, M. Microstructural characteristics of adiabatic shear localization in a metastable beta titanium alloy deformed at high strain rate and elevated temperatures. Mater. Charact. 2015, 102, 103-113. [CrossRef]

12. Trimble, D.; O'Donnell, G.E. Constitutive modelling for elevated temperature flow behaviour of AA7075. Mater. Des. 2015, 76, 150-168. [CrossRef]

13. Lin, Y.C.; Chen, X.M. A critical review of experimental results and constitutive descriptions for metals and alloys in hot working. Mater. Des. 2011, 32, 1733-1759. [CrossRef]

14. Rusinek, A.; Rodríguez-Martínez, J.A.; Arias, A. A thermo-viscoplastic constitutive model for FCC metals with application to OFHC copper. Int. J. Mech. Sci. 2010, 52, 120-135. [CrossRef]

15. He, A.; Xie, G.; Zhang, H.; Wang, X.T. A comparative study on Johnson-Cook, modified Johnson-Cook and Arrhenius-type constitutive models to predict the high temperature flow stress in 20CrMo alloy steel. Mater. Des. 2013, 52, 677-685. [CrossRef]

16. Senthilkumar, V.; Balaji, A.; Narayanasamy, R. Analysis of hot deformation behavior of Al 5083-TiC nanocomposite using constitutive and dynamic material models. Mater. Des. 2012, 37, 102-110. [CrossRef]

17. Liu, Y.H.; Ning, Y.Q.; Yao, Z.K.; Guo, H.Z. Hot deformation behavior of Ti-6.0Al-7.0Nb biomedical alloy by using processing map. J. Alloys Compd. 2014, 587, 183-189. [CrossRef]

18. Pilehva, F.; Zarei-Hanzaki, A.; Ghambari, M.; Abedi, H.R. Flow behavior modeling of a Ti-6Al-7Nb biomedical alloy during manufacturing at elevated temperatures. Mater. Des. 2013, 51, 457-465. [CrossRef]

19. Qin, C.; Yao, Z.K.; Ning, Y.Q.; Shi, Z.F.; Guo, H.Z. Hot deformation behavior of TC11/Ti-22Al-25Nb dual-alloy in isothermal compression. Trans. Nonferrous Met. Soc. China 2015, 25, 2195-2205. [CrossRef]

20. Jia, W.T.; Xu, S.; Le, Q.C.; Fu, L.; Ma, L.F.; Tang, Y. Modified Fields-Backofen model for constitutive behavior of as-cast AZ31B magnesium alloy during hot deformation. Mater. Des. 2016, 106, 120-132. [CrossRef]

21. Haghdadi, N.; Zarei-Hanzaki, A.; Abedi, H.R. The flow behavior modeling of cast A356 aluminum alloy at elevated temperatures considering the effect of strain. Mater. Sci. Eng. A 2012, 535, 252-257. [CrossRef]

22. Ning, Y.Q.; Fu, M.W.; Chen, X. Hot deformation behavior of GH4169 superalloy associated with stick $\delta$ phase dissolution during isothermal compression process. Mater. Sci. Eng. A 2012, 540, 164-173. [CrossRef]

23. Zhang, H.M.; Chen, G.; Chen, Q.; Han, F.; Zhao, Z.D. A physically-based constitutive modelling of a high strength aluminum alloy at hot working conditions. J. Alloys Compd. 2018, 743, 283-293. [CrossRef]

24. Sun, Y.; Zeng, W.D.; Zhao, Y.Q.; Zhang, X.M.; Shu, Y.; Zhou, Y.G. Modeling constitutive relationship of Ti40 alloy using artificial neural network. Mater. Des. 2011, 32, 1537-1541. [CrossRef]

25. Raj, R. Development of a processing map for use in warm-forming and hot-forming processes. Metall. Trans. A 1981, 12, 1089-1097. [CrossRef]

26. Zhang, B.Y.; Liu, X.M.; Yang, H.; Ning, Y.Q.; Wen, S.F.; Wang, Q.D. The deformation behavior, microstructural mechanism, and process optimization of PM/Wrought dual superalloys for manufacturing the dual-property turbine disc. Metals 2019, 9, 1127. [CrossRef]

27. Chen, X.M.; Lin, Y.C.; Wen, D.X.; Zhang, J.L.; He, M. Dynamic recrystallization behavior of a typical nickel-based superalloy during hot deformation. Mater. Des. 2014, 57, 568-577. [CrossRef]

28. Wu, K.; Liu, G.Q.; Hu, B.F.; Wang, C.Y.; Zhang, Y.W.; Tao, Y.; Liu, J.T. Effect of processing parameters on hot compressive deformation behavior of a new Ni-Cr-Co based P/M superalloy. Mater. Sci. Eng. A 2011, 528, 4620-4629. [CrossRef]

29. Chen, F.; Liu, J.; Ou, H.G.; Liu, B.; Gui, Z.S.; Long, H. Flow characteristics and intrinsic workability of IN718 superalloy. Mater. Sci. Eng. A 2015, 642, 279-287. [CrossRef]

30. Sellars, C.M.; Mctegart, W.J. On the mechanism of deformation. Acta Metall. 1966, 14, 1136-1138. [CrossRef]

31. Mcqueen, H.J.; Ryan, N.D. Constitutive analysis in hot working. Mater. Sci. Eng. A 2002, 322, 43-63. [CrossRef]

32. Zener, C.; Hollomon, J.H. Effect of strain rate upon plastic flow of steel. J. Appl. Phys. 1944, 15, $22-32$. [CrossRef]

33. Sargent, P.M.; Ashby, M.F. Deformation maps for titanium and zirconium. Scr. Metall. 1982, 16, 1415-1422. [CrossRef]

34. Zhao, H.Z.; Xiao, L.; Ge, P.; Sun, J.; Xi, Z.P. Hot deformation behavior and processing maps of Ti-1300 alloy. Mater. Sci. Eng. A 2014, 604, 111-116. [CrossRef] 
35. Nie, X.A.; Hu, Z.; Liu, H.Q.; Yi, D.Q.; Chen, T.X.; Wang, B.F.; Gao, Q.; Wang, D.C. High temperature deformation and creep behavior of Ti-5Al-5Mo-5V-1Fe-1Cr alloy. Mater. Sci. Eng. A 2014, 613, 306-316. [CrossRef]

36. Warchomicka, F.; Poletti, C.; Stockinger, M. Study of the hot deformation behaviour in Ti-5Al-5Mo-5V-3Cr-1Zr. Mater. Sci. Eng. A 2011, 528, 8277-8285. [CrossRef]

37. Prasad, Y.V.R.K.; Gegel, H.L.; Doraivelu, S.M.; Malas, J.C.; Morgan, J.T.; Lark, K.A.; Barker, D.R. Modeling of dynamic material behavior in hot deformation: Forging of Ti-6242. Metall. Trans. A 1984, 15, 1883-1892. [CrossRef]

38. Prasad, Y.V.R.K.; Rao, K.P. Processing maps and rate controlling mechanisms of hot deformation of electrolytic tough pitch copper in the temperature range 300-950 ${ }^{\circ} \mathrm{C}$. Mater. Sci. Eng. A 2005, 391, 141-150. [CrossRef]

39. Dikovits, M.; Poletti, C.; Warchomicka, F. Deformation mechanisms in the near- $\beta$ titanium alloy Ti-55531. Metall. Mater. Trans. A 2014, 45, 1586-1596. [CrossRef]

(C) 2020 by the authors. Licensee MDPI, Basel, Switzerland. This article is an open access article distributed under the terms and conditions of the Creative Commons Attribution (CC BY) license (http://creativecommons.org/licenses/by/4.0/). 